\title{
Environmental Learning Using a Problem-Based Approach in the Field: A Case Study of a Hong Kong School
}

\author{
Tammy Kwan \\ Faculty of Education, The University of Hong Kong, Pokfulam, Hong Kong
}

\section{Max So}

St. Stephen College, Stanley, Hong Kong SAR

This study investigated the environmental learning of a group of senior geography students through a problem-based learning (PBL) field programme to see if the goals of education for the environment could be accomplished. In the PBL field programme, the students were given a problem statement concerning a real-life scenario of an old lady living in a remote village of Hong Kong. During the PBL field programme which also has adopted an action research framework, the students were observed to have identified the problem statement, set hypotheses, constructed the research methods and collected empirical data in an authentic environment all by themselves. This paper reports on the first cycle of this piece of action research. Data were collected both quantitatively and qualitatively via questionnaires, students' reflective journals, field observation notes and group interviews. The initial finding of this PBL field programme reveals that students had acquired more in-depth knowledge and extended their comfort zones in learning. They were able to develop and practice their critical thinking and problem-solving skills while they were working on the problem in the field. Although there was no evidence of sustained self-directed learning among the students, the PBL field programme offered them a framework for developing self-directed learning. An initial conclusion is that PBL in the field can provide a useful framework and direction for EE to accomplish the goals of education for the environment.

doi: 10.2167/irgee230.0

Keywords: action research, environmental learning, fieldwork, problem-based learning (PBL)

\section{Introduction}

Environmental Education (EE) is seen as a key solution to resolve the increasing severity of environmental problems and conflicts. In the past decades, a paradigm shift has been taking place in EE. Initially focused on education about and in the environment, there came the promotion of education for the environment, which emphasises the development of critical thinking and problem-solving skills through critical study of real-life environmental issues and problems (Fingle \& Torp, 1995). This approach requires learners to be actively involved in a variety of practical learning experiences, as revealed in 
major environmental documents such as the Belgrade Charter, Agenda 21 and the Hong Kong Guidelines on EE in Schools (CDC, 1999). Recent educational reform in Hong Kong (CDC, 2000; EMB, 2005) urges a pedagogical shift towards student centredness because conventional classroom learning is no longer seen as able to accomplish fully the goals of education for the environment. Thus, we would like to explore pedagogical approaches and teaching methods that will bring environmental learning closer to the expectations of this educational reform.

A traditional pedagogical EE approach that focuses on the cognitive domain seems unable to meet the expectations of the Hong Kong Education Reform and Guidelines (CDC, 1999, 2000; EMB 205) stated above. In attaining the goals of education for the environment, problem-based learning (PBL) seems to be an effective learning and teaching strategy to accomplish this aim. PBL transfers the active role in learning to students in that it uses an authentic, complex problem as the impetus for learning and fosters the acquisition of interdisciplinary knowledge, group work, critical thinking and problem-solving skills (Bligh, 1995; Casey \& Howson, 1993; Dolmans \& Schmidt, 1994; Gallagher et al., 1994; Johnson \& Johnson, 1979). This approach was first adopted in medical education and training but is now commonly used globally in higher education in various disciplines and also in secondary school learning environments. For instance, Wheeling Jesuit University, supported by the National Aeronautics and Space Administration (NASA) to create the Classroom of the Future, has developed the Exploring the Environment (ETE, 2005) online series in EE. The modules and activities in the ETE series are based on real-world situations and the students use PBL as a principle learning strategy and vehicle to investigate scientific, social, political, and cultural aspects of controversial, authentic environmental problems. Unlike the traditional approach, this constructivist learning approach provides opportunities for students to have full control over their learning, thus making it more meaningful. They develop their own questions from the problem and solve the problem by themselves. By doing so, students do not need to memorise materials that they do not fully understand or are not able to apply (Ayres, 2002).

\section{The contextual background of the problem-based learning field study}

This study concerns the innovative use of a PBL field programme organised by a geography teacher (one of the researchers) on a 2-day field camp held in a remote village (Lai-Chi-Chong) of Hong Kong (based on Chan, 2003-05). The village is located along a shoreline that has many significant geological features and is a popular field site for geographical and EE. The PBL field programme involved a class of 21 Secondary Six (equivalent to years 11-12) geography students divided into three groups, and each group was led by a facilitator. Two of them were biology and geography teachers of the school and the other was a postgraduate student. All the facilitators had the opportunity to attend a PBL field learning programme to experience the PBL process as a learner themselves, and hence they were all fully aware of their facilitating role instead of information provider or problem solver role to the students when they engaged in this 2-day PBL field programme. 
Table 1 Environmental characteristics and classroom learning performance of the seven students

\begin{tabular}{||c|c|l|l|l||}
\hline \hline & $\begin{array}{c}\text { ETP } \\
\text { score }\end{array}$ & Environmental belief & Environmentalism & $\begin{array}{l}\text { Classroom learning } \\
\text { performance }\end{array}$ \\
\hline A1 & 16 & Environmental protection & Dark green & $\begin{array}{l}\text { Active, responsive, } \\
\text { clever }\end{array}$ \\
\hline A2 & 6 & Environmental protection & Red-green & Generally passive \\
\hline A3 & 13 & Economic growth & Dark green & Very quiet and passive \\
\hline A4 & 8 & Environmental protection & Red-green & Passive \\
\hline A5 & 12 & Environmental protection & Red-green & Generally passive \\
\hline A6 & 15 & Economic growth & Dark green & Passive \\
\hline A7 & 0 & Neutral & Neutral & Passive \\
\hline
\end{tabular}

This paper reports in detail how one group of seven students (taught and facilitated by the geography teacher who is also the co-author of this paper) consisting of three boys and four girls (A1-A7) experienced environmental learning through the initial and innovative use of PBL in the field. The seven students' environmental characteristics, based on a validated environmental questionnaire (Stimpson, 2001) conducted two weeks before the PBL field programme, and also their usual classroom learning behaviour which is the impression obtained by their geography teacher who has taught them for 2 years, are described in Table 1. Detailed explanation of the questionnaire and the environmentaltechnological paradigm (ETP) scores can be found in the appendix.

\section{The scenario of the problem statement}

The PBL field programme was based on a real-life scenario that happened in Lai-Chi-Chong, a remote rural village in Hong Kong (Chan, 2003-05). The situation involved a social-environmental issue whereby Madame Ho, an elderly lady residing in the sparsely populated village, requested the Government to build a footpath from the pier to her house. But her request was rejected. The following is the problem statement given to the students as the basis for group discussion and investigation in the PBL field programme:

Madame Ho, 70, used to live in a self-built stone house at Lai-Chi-Chong. She moved to live with her sons two years ago. However, she still makes regular weekend visits to her house, by getting to Ma-Liu-Shui Pier and taking the ferry to Lai-Chi-Chong. After getting off the ferry, she has to walk along the shoreline for nearly an hour from the pier to her house. The rugged shoreline is her only accessible route. At high tide, a considerable part of the shoreline is submerged and she has to painstakingly climb over the adjacent slopes in order not to get wet. However, some slopes are loose and fail easily. Because she suffers from rheumatism, Madame Ho finds it difficult to walk for such a long distance especially at high tide. Finally, she wrote a letter to the Home Affairs Department of her district, 
requesting the construction of a paved footpath from the pier to her house. The Department rejected her request.

Lai-Chi-Chong is an area of great geological interest in Hong Kong because of its unique volcanic deposits and tectonic features. This site is often visited by local geologists, teachers, and students from universities and secondary schools. The footpath requested by Madame Ho would be built in this area. Construction of the footpath is expected to cause damage to the unique geological features, for instance, folds on the ground surface would be buried by concrete and so on. This social-environmental conflict in land use presents an interesting issue for initiating environmental learning through using a PBL approach in a real environmental field problem.

Based on Lin et al. (2003), the participating students were expected to:

- identify the problem of the land use conflict;

- investigate the problem;

- collect authentic data from the field;

- analyze the data;

- suggest solutions to resolve the conflict; and

- justify their findings and suggestions.

We believe that such PBL learning experiences could develop students' environmental knowledge and skills as well as help to clarify their values and attitudes (Bogner, 1998; Hungerford \& Volk, 1990) towards accomplishing the goal of education for the environment (Fien, 1993).

\section{Research Methods and Data Collection}

This study employed both qualitative and quantitative approaches to collecting data on students' PBL learning experiences. The qualitative data includes onsite participatory observations and field notes, students' writing post-field programme reflective journals and attending a group interview that allowed us to acquire a deeper understanding of students' environmental learning processes and outcomes in the PBL programme. The quantitative data emanated from two questionnaire surveys. The first questionnaire conducted 2 weeks before the PBL field programme was designed to reveal students' environmental attitudes and to understand students' behaviours (Stimpson, 2001). The second questionnaire was conducted after the PBL field programme as a post-activity evaluation to collect feedback from the students towards using PBL to do environmental fieldwork.

\section{Students' Learning Activities in the PBL Field Programme}

Seven stages identified throughout the 2-day PBL field camp programme were experienced by this group of seven students.

\section{Stage 1 The first indoor group discussion (1 hour)}

At the beginning of the PBL field programme, the students were given the problem statement. They spent 15 minutes identifying most of the facts and ideas 
from the problem statement and then the remaining 45 minutes on proposing hypothesis.

The students agreed that it was worth investigating whether the present shoreline was "difficult to walk" for the elderly lady. They also wanted to find out why the government refused Madame Ho's request. By the end of this stage, the following hypotheses were set:

(1) The present shoreline is difficult to walk through.

(2) The government refused Madame Ho's request because the proposed footpath is not cost-effective.

(3) The government refused Madame Ho's request because the proposed footpath may cause considerable damage to the environment.

The group members also identified several factors that they had to understand when testing their hypotheses. For example:

- the tidal range of the coast;

- the weathering of coastal rock; and

- the ecologically endangered species of the coastal area.

These factors helped the students to delimit and structure their study in the actual environment of the coastal area. The students needed to have a better understanding of the relevant geographical setting, such as the meaning and effect of tides, in order to test their posed hypotheses.

During their first stage of PBL group discussion, we noticed that all students were generally very responsive to each other's suggestions. When the students were first confronted with the problem statement, they did not appear to know how to handle it. But eventually three students (A1, A2 and A5) emerged to take up a leadership role in the discussion. In normal classroom learning, A1 was seen as a clever, active student who asked the teacher many questions related to geography. After class, he liked to offer help to his classmates concerning the subject matter. It was therefore natural to expect A1 to become the group leader. But we were taken by surprise by the active participation of A2 and A5 who made lots of suggestions during the discussion. In school, however, they were not outstanding and could be described as passive students. They seldom raised questions or answered teachers' questions. Their motivation during this PBL discussion was obviously greatly enhanced. Based on the observation of one of the researchers, who also had been their geography teacher for 1 year, it was unusual to see so many students being actively involved in learning and discussion about the scenario of the problem statement. Student A3, however, did not contribute any idea but just listened quietly throughout the whole discussion.

\section{Stage 2 Onsite field exploration (45 minutes)}

After the lunch-break following the discussion, the students were taken to the shoreline in question. The students followed the walking route of Madame Ho from the pier to her house along the shoreline. This walk offered the students an opportunity to observe the real shoreline geographical environment of the shoreline that Madame Ho had to negotiate, and they stopped to observe and 
to discuss the tidal range. They wanted to know if the high tide level would affect Madame Ho's route. The following is part of their dialogue (all dialogues quoted are translated to English from Cantonese):

A1: (pointing to the boulders) There are boulders. They should have been dumped by waves during storms. That should be the high tide level.

A2: Typhoons dumped those boulders there?

A1: I was told about that in my last trip to Tung Lung Island (pointing to the sand). Now, we know the seawater should reach up to this level. This part is still wet. The high tide level should be somewhere here.

A3: That means Madame Ho can walk through this part of the shoreline even when it is at high tide. (A1 and A2 were walking towards the coastal slope and found a vague trail mark.)

A2: Clearly, this is a footpath and it is easy to walk.

A6: (showing sympathy) Walked by Madame Ho?

A3: We can try to walk through it (the trail mark) and then walk along the shoreline too.

(When they walked along the shoreline, A2 found a line of seaweed deposited on the shoreline.)

A2: (pointing to the line of seaweed) The seaweed was washed up by ocean waves and they were deposited here. Clearly, this is the high tide level.

A1: This should be the normal high tide level. When there is a typhoon, the tide level will be higher.

It is evident that the students had obtained a better understanding of tides and the different tidal levels. Their dialogue was based on what they could observe in the real environment and also referred back to their 'previous' knowledge about the tides. Moreover, the group was interested in the coastal rocks, particularly the patterns, layers and colours. A1 showed his keen interest in geology as he often stopped and observed the rocks carefully. When the whole group stopped at a point to recheck the tide level, A3 discovered a large fold in the rocks, one of the geological landmarks in Lai-Chi-Chong. The group spent a few minutes discussing this feature. Some of them tried to use what they had learned in the classroom to explain its formation.

The stage of onsite field exploration lasted for about an hour. All students seemed to have enjoyed this stage very much in the field. A1 and A2 appeared to have a stronger sense of curiosity in nature while A3 and A6 showed a stronger involvement towards considering the preset hypotheses and environmental factors which also helped them to focus their field exploration. In general, all students appeared to be more aware of what they had seen in the environment (for example, the line of seaweed) and were able to make inferences about the degree of difficulty of Madame Ho's walking route. The careful and thorough observation shown by the students had never been noticed by their facilitator when they were engaged in doing the conventional 'look and see' types of field 
trips. The students appeared to have a stronger sense of awareness of the environment and were more self-initiated and motivated in using their geographic knowledge to explain the observed features and environmental factors related to the problem statement.

\section{Stage 3 The second onsite group discussion (30 minutes)}

After the onsite field exploration, the whole group sat outside Madame Ho's house and began their second (onsite) group discussion. The facilitator reminded them to generalise what they had seen and experienced so far and to suggest possible ways to collect data to test their hypotheses.

Based on the observation of the seaweed position and the vegetation pattern, the students came to the conclusion that the shoreline is still accessible during high tide. Most of them expressed that they did not have great difficulty walking along the shore, and they believed the proposal of constructing a footpath along the shoreline by Madame Ho was a personal request. But A4 and A6 had greater sympathy for Madame Ho. They thought Madame Ho might have greater difficulty to walk the route because she suffered from rheumatism. A1 also pointed out that the proposed footpath might be beneficial to other visitors, particularly if the area is designated as a geological reserve. No student in the group expressed a strong stand during the discussion but they tended to accept the government decision of not building the footpath.

To test their hypotheses, they decided to use a scoring system to quantify the difficulty of walking along the shore. They set up several checkpoints from the pier to Madame Ho's house. A checkpoint was set wherever it appeared to be difficult to walk through. In addition, A4 proposed to conduct a questionnaire survey to predict the cost-effectiveness of building the proposed footpath.

This outdoor discussion lasted for about 30 minutes. The learning motivation did not appear as strong as it was during the first stage of the previous in-house discussion. Most students were involved in deriving a methodology to test the hypotheses, but the discussion was quite sporadic. They also sought more advice from the facilitator especially in the first 10 minutes. We believed there were two reasons for this student behaviour. The students had no previous PBL experience in any scientific investigation. Moreover, the place and the time for holding the onsite discussion were less than ideal. On that day, the weather was hot, sunny and humid with lots of mosquitoes. It is believed that the unfavourable environment was a negative effect on their commitment to engaging in a discussion. However, we found that the students (e.g. A1, A2 and A5) who had more outdoor countryside experience were less affected and managed to lead the discussion. Yet, the others who had less experience in the countryside (e.g. A3, A4 and A7) were significantly affected by high temperature and mosquito bites.

\section{Stage 4 Data collection (1 hour 15 minutes)}

The students devised two surveys to collect data from the field environment. To measure the difficulty of walking along the shoreline, they selected five checkpoints. At each checkpoint, they measured four factors, namely the roughness, the slipperiness of the coastal rocks, the gradient and the stability of 
the coastal slope. The facilitator offered technical assistance to the students in data collection, for example, the provision of an Abney Level or an orienteering compass for measuring gradient on the coastal slope. To quantify the other three factors, the students constructed a Likert scale ranging from 1 to 5 to describe the roughness, slipperiness of the coastal rocks and the stability of the coastal slope. Based on their field exploration, they gave a score to each of them. A4 and A7 volunteered to construct a questionnaire to collect data on how frequently the coastal area is being visited. They also took the initiative to interview several visitors on the pier and a few local villagers they met during the site observation.

We noticed a significant improvement in students' involvement in this stage of the data collection. The students made a clear division of work. A1, A2 and A3 were very keen in using the Abney Level and the compass, according to their abilities and preferred learning traits (Gardner, 1993). A6 who previously was a shy student in school, volunteered to interview a few visitors and local villagers. The teacher and her peers were quite surprised by her committed behaviour in taking part in the data collection. It seemed that her comfort zone of learning had been greatly extended in this PBL field programme.

\section{Stage 5 The third indoor group discussion (45 minutes)}

The students self-organised another discussion on the first evening of the PBL field programme because they wanted to organise and analyze the field data collected to prepare for a group presentation the following day. They also wanted to test their hypotheses in a discussion that was divided into two parts. All students expressed the view that they had no difficulty in walking the shoreline from the pier to the house. They therefore decided to reject the first hypothesis - the present shoreline is difficult to walk through. However, they admitted that walking the shoreline may not be difficult for them but could be quite difficult for Madame Ho because she is old and suffers from rheumatism. Because they were unable to collect data directly from Madame Ho, they could not make further comment on that issue. During the group discussion, they spent more time in discussing the hypothesis related to the cost-effectiveness of building the proposed footpath. The students decided that a decision about the construction of the proposed footpath required the consideration of the following factors:

- the construction costs;

- the location of the footpath (either close to the slope or out on the shore); and

- the impact of the footpath location on the environment.

It was particularly impressive to follow their discussion on the location and the environmental impact of building a footpath along the shoreline. The dialogue below shows how they discussed if the proposed footpath should be built near the hill slope or farther out on the fore shore.

A1: Most geological features are found near the shore. We found no obvious feature near the slope. Building the footpath near to the slope will cause less damage to these features.

A5: If the footpath is built near the shore, visitors can see the geological features easily.

A6: But if the footpath is built there, the beach will be gone. 
A5: If the footpath is built for visitors (not only for Madame Ho), it should be oriented to their need. If the footpath is built near the slope, the visitors may not be able to see them (the geological features).

A1: But it will cause damage to the geological features.

A4: Yes.

A5: We can build a bridge then.

A1: But the stands of the bridge will still cause damage.

A2: When we walked from the slope to the shore in this afternoon, we had no difficulty.

A1: If we built the footpath on the shoreline, it will cause damage to those physical features.

A5: But if there is a footpath near the shoreline, the rubbish deposited on the shoreline can be cleared easily. Anyway, when we build a footpath there, it will cause damage.

A6: That's why we need to know the costs and benefits of building the footpath.

This dialogue indicated the active sharing among all of the group members except A3 who still adopted his listening mode and did not get involved at all in the discussion. A7 concentrated on her recording duty and did not appear to have said much in the discussion. On the whole, the discussion was open-ended and fruitful though the group did not actually have any conclusion to the other hypothesis on 'building the footpath is not cost-effective and will cause considerable damage to the environment'.

It was obvious that the students wanted to find out the complexity of environmental impacts of building the footpath to the shoreline. Although their ideas were disorganised and sometimes misconceptions occurred, it was evident that the students had extended their environmental concerns and they were able to think more critically. This can be indicated from the justification made by A1 on building the proposed footpath near the slope as follows:

Personally, I think the construction of the footpath does not have much impact on the environment. Based on what I've seen today, those living organisms seemed to be ordinary. The trees near the slope can be found anywhere. It seems that they do not have particularly high ecological value... If the government is really going to build a footpath, it should be built near the slope. . because most geological features are found near the shore. We found no obvious feature near the slope. Building the footpath near to the slope will cause less damage to these (coastal geological) features. (A1)

\section{Stage 6 Short onsite field trip (1 hour)}

A short field trip was arranged the next day for the students by the three facilitators to offer information on the geology of Lai-Chi-Chong. This was deliberately held on the second day of the PBL field programme after the students had been given full autonomy to decide by themselves what to do in the first day from Stage 1 to Stage 5. Then the students were in a better position to have 
the desire and motivation to learn new geological information and to acquire new understanding to help them refine what they had discussed in Stage 5. The facilitators were aware of the shortcomings of the conventional field trip; therefore, they did not just provide such new information by telling or explaining. Instead, they created an inquiring atmosphere by posing questions to stimulate more critical thinking among the students. This field trip focused on learning about two geologic aspects: the volcanic deposits and the coastal weathering along the shoreline. The seven students of the targeted group gave keen and fast responses to the facilitator's questions though some of the answers were incorrect. The responses were particularly encouraging when they were asked to describe and explain an exposed soil profile on a coastal slope. It should be noted that the students were studying soils in their geography lessons in school during that time. Before the 2-day field camp of this PBL programme, the teacher conducted soil fieldwork with the students in school. At that time, the students were apathetic and were not willing to use their hands to touch and feel the soil texture, especially the girls. But the morning when the facilitator asked them to do the same in the field, they were all very willing to do so. A2, A3, A4 and A6 even passed the soil samples around and played with them.

The facilitator was quite impressed by the students learning motivation, learning performance and active participation during this short field trip. The overall learning atmosphere was enjoyable, energetic and dynamic. Not only had they asked more questions than times when they were engaged in conventional field trips but also their questions were more critical and in-depth than before.

\section{Stage 7 Group presentation (15 minutes each)}

The short field trip was followed by the last stage of group presentation on their work done in the 2-day PBL field programme. Each group was given 15 minutes to report on their work progress. All the three groups had concluded that they had little difficulty to walk through the present shoreline and they tended to accept the government's decision to refuse Madame Ho's personal request. The students, however, did not make a decision about whether or not the footpath should be built. They felt they needed to collect a more comprehensive set of data on the cost-effectiveness and the environmental impact of the proposed footpath before a sensible decision could be made. They would like to know more about the number of visitors and the ecological value of the organisms found along the shoreline.

On the whole, the students of this study group had demonstrated a more impressive learning behaviour in the PBL field programme. They used their existing knowledge sensibly to explain observed field phenomena in order to verify their hypotheses set for the scenario of Madame Ho. They were able to determine what new data they needed before an informed decision could be made. The section below will discuss in greater detail how using PBL in the field can generate and bring about education for the environment.

\section{PBL in the field to actualise education for the environment}

Through the use of PBL in the field to study an environmental issue, students were encouraged to develop responsible environmental behaviours (REB) 
(Hungerford and Volk, 1990). This section seeks to reveal students' environmental attitudes, the development of their environmental knowledge, critical thinking and problem-solving skills during the PBL field programme and use them as evidence that doing PBL in the field seems to accomplish the goals of education for the environment.

\section{Review of students' environmental attitudes from the PBL field programme}

Through investigating the case of Madame Ho, we had a chance to observe students' environmental position along a continuum between ecocentricism and anthropocentricism (Fien, 1993). As revealed in Table 1, students who score high in the ETP score tend to be more ecocentric; thus, they should have a stronger environmental concern in regard to building the footpath. On the contrary, students with a lower ETP score tend to be more technocentric and anthropocentric and are likely to show more concern for Madame Ho. The association between the ETP score and a student's environmental position was revealed clearly in the first indoor group discussion.

When the students were discussing whether or not a footpath should be built for Madame Ho, A2, with a low ETP score of 6, believed that it should depend on its usage, the difficulty of construction and the cost-effectiveness. He did not take the environment into his consideration and, hence, reflected his anthropocentric position. Yet, those who have a higher ETP score, in particular A1 and A5, had prioritised the environmental impact of building the proposed footpath as their major concern. A1 wanted to know if the area contains species of high ecological value before deciding about whether or not to build the footpath. A5 pointed out that it might affect the coastal morphology and the ecological balance of the area. This reflected their favourable environmental position. However, their environmental stand did not seem to be supported by their strong and sound environmental knowledge. For instance, A1 believed that the proposed footpath might deteriorate the water quality while A5 was unable to describe the possible effect of the proposed footpath upon the local ecology.

As expected, it was not possible for us to recognise any attitudinal shift in environmental position among the students in this first cycle of the PBL field programme. However, previous research on attitude indicates that using PBL in the field might lead to attitudinal change as a result of three factors: cognition, affection and behaviour (Baron \& Byrne, 1994; Mouly, 1973; Rosenberg \& Hovland, 1960). Below is the discussion we put forward to see if such a claim is justified.

\section{Cognition}

By engaging students in scientific inquiry, they learn strategies for scientific thinking and develop skills in problem solving. In this PBL field programme, when the students generated ideas and hypotheses, they had to describe the problem in detail, evaluate information from different perspectives to resolve the problem critically, and design a feasible data collection mechanism which could be applied to test their hypotheses. Through this scientific inquiry approach, students obtain new information that may change their original ideas or deepen their previous conceptual understanding (Minstrell, 1989; Rosebery et al., 1992). 
As a result, the scientific inquiry method helps attitudinal development (Clark, 1973). To some extent, the effects of this PBL field programme on students' attitudinal change can be reflected from the students' group interview:

I've learned the way to solve problems scientifically. Traditional way of learning mainly comes from teachers who are supposed to provide 'facts' to students. Whether or not they are facts are doubtful. . . Learning is more consolidated as I can feel and experience the real things (soils and their horizons)... Learning is more authentic. What we see in the field can help consolidating our understanding on the environment. (A1 - group interview)

Fieldwork and data collection are the most useful parts to me as I can see many things and realise the ways to solve a problem. (A7 - group interview)

Such attitudinal change can also be revealed in the students' reflective journals:

... the greatest gain was that each of us thinks of the problem from different perspectives and with different roles, looks at the issue objectively and makes responses. (A4 - journal data)

This was my first time to join a geography field camp. I learned a lot and recalled what I had learned in the past. . Although the weather was very hot and there were many mosquitoes, I think the learning process was very meaningful. Each group mate was assigned a role and they had expressed many opinions... Not only I had learned geography but also developed problem solving skills and teamwork. (A6 - journal data)

Hungerford and Volk (1990) mentioned that the development of in-depth knowledge and problem-solving skills can strengthen the students' ownership of the knowledge and empower their use of such knowledge in new situations. In this study, the students exhibited their development of in-depth knowledge by recalling what they have learned before and projecting what they needed to know more about in order to make the decision about constructing the footpath for Madame Ho. They also constructed their research tools for quantifying and assessing the walking difficulty of the shoreline as well as the cost-effectiveness of the proposed footpath. Accordingly, this kind of learning experience should impose a positive impact on the formation of responsible environmental behaviours or understanding the multifaceted issues that underlie environmental problems and concerns.

\section{Affection}

Research on outdoor education reveals direct nature experiences have fostered positive environmental attitudes (Bogner, 1998; Hungerford \& Volk, 1990). This finding was reinforced by the result from the post-PBL field programme questionnaire. All participating students expressed their positive feelings about their learning experience in this PBL field programme. This is consistent with the fact that all students had positive feelings after outdoor activities. As pointed 
out by Clark, "emotional experiences are one of the factors contribute to attitudinal change" (Clark, 1973: 25). Good emotional experiences usually result in favourable attitudes. For example, we noticed that A6 had extended her comfort zone towards working in a difficult environment. When her geography teacher asked her to feel the texture of the soil sample in school, she was reluctant to do so. But in the group interview, she commented:

In the past, I was not willing to touch and explore things in the wild. But now, I'm more willing to do so... the soil is so funny, I can mold it into various forms of shapes. (A6 - group interview)

To a certain extent, the students have become more sensitive to their environment. Such increase in the environmental sensitivity, as suggested in Hungerford and Volk's (1990) model, favours the development of responsible environmental behaviours. Bogner (1998) also points out that outdoor education can indeed cultivate students' environmental learning in an affective way as it develops students' attitudes, responsibilities and appreciation towards nature and the environment.

\section{Behaviour}

In an earlier environmental attitude questionnaire conducted before the PBL field programme, almost all students had 'medium' to 'strong' desire to improve the environment. Throughout the seven stages of the PBL field programme discussion, most of the participating students had raised their environmental concern about deciding if a footpath should be built. This can also be reflected from the factors that they identified which had strong connections to the ecological value of the area.

Although it is generally assumed that students who have a strong desire to improve the environment will behave in a more environmentally friendly way (Hungerford \& Volk, 1990), this was not always the case in this study. When the students were collecting data in the field during Stage 4, A3 (the quiet passive student) threw away his plastic water bottle on the shore and then left. It was noted that A3 had expressed a 'very strong' desire to improve the environment in the environmental attitude questionnaire. When we asked him during the interview why he did that, he and his group mates gave the following responses:

Researcher: You threw away a plastic water bottle while your group mates were collecting data in the field, why did you do that?

A3: $\quad$ I don't know.

A5: $\quad$ He said there was lots of rubbish on the shore. So, it didn't make a difference if there was one more bottle.

A3: $\quad$ I tried to test if it was windy. But when I wanted to pick it up, I found the bottle was too far away from me.

A5: $\quad$ That day was not windy.

A2: $\quad$ After he (A3) had thrown the bottle, he didn't look back. 
A1:

I asked him to pick up another bottle for compensation but he did not do that.

Researcher: In the questionnaire, you said you had a strong desire to improve the environment. Why is there such a conflict?

A3: I don't know how to answer this question.

Similar discrepancies between environmental attitudes and behaviours were experienced by Palmberg and Kuru (2000) in a 1-day outdoor camp in which some of their students whittled at living trees. Two of them were scouts and both enjoyed outdoor activities. Palmberg and Kuru believed these conflicts may be explained in terms of conscious and unconscious action and the students had not yet reached the level of applied knowledge. The response of A3 revealed that he did not seem to have an internalised locus of control. He provided an exemplar showing that even if an individual claims to have a strong environmental attitude, it does not imply this person can always behave and act in an environmentally responsible manner.

Students who had higher environmental scores seemed to have a stronger levels of environmental awareness during the different stages of group discussion. They said that they had enjoyed using PBL as a learning strategy in the field, and they had positive feelings on their empowered learning experiences as revealed in the post-PBL field programme questionnaire, reflective journals and the group interview. A few students had extended their comfort zone of learning towards the environment. But we also noticed that strong environmental attitudes might not necessarily be associated with responsible environmental behaviours. Students may sometimes have unconscious behaviours which could cause damage to the environment. This seems to be contradictory to the knowledge-attitude-behaviour theory (Ramesy \& Rickson, 1976: 10) which states that 'increased knowledge leads to favourable attributes towards the environment which in turn leads to action promoting better environmental quality.' We also found that the students' environmental attitudes were not very stable and they seemed to be susceptible to change quite easily.

\section{Development of environmental knowledge in an authentic setting}

When students worked on the problem statement in the first indoor discussion, we observed that they generally had more concerns about the environmental impact of the proposed footpath. Most students agreed or at least did not deny that the construction might lead to environmental problems. The group believed it would lead to pollution and ecological disturbance during its construction. Littering might be more serious if there were more visitors using the footpath. In this early stage of the discussion, most of their ideas can be described as disorganised, negative, vague, abstract and piecemeal.

After generation of the hypotheses and the related learning issues, the students were led to the shoreline to collect data and test their hypotheses. While they were actually in the field, we noticed that the students were more observant than when they were asked to work in conventional field trips where the teachers did most of the talking. But in this PBL field programme, students appeared to be intrinsically motivated and self-directed to find evidence related to their hypotheses and learning issues. They demonstrated higher levels of autonomy 
in learning. In fact, PBL in the field exposes students to complexity and reality. In the field, the students realised that their knowledge and skills were inadequate to describe or explain fully an observation. This created a learning gap that they wanted to narrow. The following are some questions and concerns posed by the students when they walked along the shoreline:

- Is it an asymmetrical fold?

- Why are there colour patterns in the rock?

- Why do the rocks have different colour?

- I don't know if the rocks are valuable.

- How do we describe the location that we are standing now?

- How can we identify plants? How do we know if they are ecologically valuable?

- I don't know how to describe that outcrop of rock.

During Stage 6 of the short onsite field trip held on the second day, the group facilitator intended to guide the students to find out answers to the above questions which were raised by them. We noticed that the students were very attentive and motivated. When they obtained a possible answer to a specific question, they did not stop their inquiry at that point. Instead, they posed further questions. The students' active responses seem to validate the contention of Evenson and Hmelo (2000) that narrowing the learning gap induces students' intrinsic motivation to learn further.

In order to determine the high tide level, A1 and A2 believed that it could be indicated by the coastal rocks if they were wet. But when they were in the field, they discovered that it was easier to identify the high tide level by observing the position of seaweeds and rubbish that were left on the shore.

Field observation is the most useful part to me... Before going to the field, I thought that it's easy to identify the high tide level. But when I went to the field, it's another story. (A2)

It is not surprising but indeed expected that students change their ideas when they are unable to fully describe or explain an observation. Hewson and Thorley (1989) believed that students change their ideas when they discover alternatives that seem plausible and appear to be more useful. Besides, learning in the environment with an inquiry attitude challenges students' common belief in science as they often think of it as a mere collection of facts and explanations. This approach allows students to develop their abilities to inquire and strategies for scientific thinking (Linn et al., 1989) as revealed in the dialogues included in Stage 2 through Stage 5.

Learning in the field exposes students to greater complexity and challenge. Dewey (1938) argued that what makes an experience educational is whether there is room created for further growth. Vygotsky (1978) queried if students' learning should only be operated within their zones of proximal development. In other words, should students be challenged to go beyond what they could do? Along this line of thinking, it seems that learning in the environment can provoke students to such challenge by extending their zones of proximal development. 
To conclude, this PBL field programme offered a framework for students to develop in-depth environmental knowledge. The investigation focused on their hypotheses and factors identified. They learned and reduced the learning gaps by authentic knowledge and experience. In addition, the PBL field programme prompted students' inquiry learning and scientific thinking abilities. It also exposed the students to greater complexity and the challenge of understanding and experiencing environmental knowledge for the environment.

\section{Development of critical thinking and problem-solving skills}

The PBL scenario of Madame Ho encouraged the students to experience learning through a scientific inquiry approach. They identified facts and ideas from the scenario critically. They identified the problem and set their own hypotheses and defined learning issues. Their learning was guided by the questions posed by them in Stage 1 and to them in Stage 6. In Stage 3, they decided on their own research methods and constructed instruments to collect empirical data which was used to support or reject their decision. Though they did not provide a tentative solution at the end, the PBL learning experiences offered them many opportunities to develop their problem-solving skills. For example, the students needed to find an appropriate data collection method to prove if the present shoreline is difficult to walk through, and they also needed to determine whether it would be the cost-effectiveness to build the proposed footpath. When they encountered these problems during PBL, they were indeed applying and developing their problem-solving and critical-thinking skills. They thoughtfully considered different views, challenged or negotiated with others' ideas, and evaluated the possibility and feasibility of different options. A7 was a group recorder so she did not involve herself much in the actual group discussion; however, she stated in the group interview that:

Fieldwork and data collection are the most useful parts to me as I can see many things and realise the ways to solve a problem. (A7 - group interview)

Other students also expressed in the group interview and their reflective journals that:

This PBL programme can help me improve my answering skills. When I answered questions in the past, I might put some subjective views and feelings into it. But now, I have learned how to be more objective in answering questions by looking into the different perspectives. (A5 - journal data)

Moreover, A4 expressed the feeling of being empowered during the problemsolving processes.

It's a learning activity that gives real freedom to students in problemsolving. It gives us incentive to explore and learn actively. (A4 - group interview)

According to Hungerford and Volk (1990), such a feeling of empowerment can help internalise students' locus of control. Besides, they pointed out that 
education for the environment can be attained when opportunities are provided for learners to acquire in-depth knowledge on ecological concepts and their interrelationships, to develop analytical and observational skills, and to apply these skills successfully. Apparently, using PBL in the field seems able to accomplish the goals of education for the environment.

\section{Development of Self-Directed Learning}

PBL is a process that encourages learners to take the initiative to learn (Ayres, 2002). The PBL field programme offered a general framework and an opportunity for students to play an active role in developing a self-learning strategy to think critically and inquire scientifically, and to describe an observation and to explain a decision. Their learning was empowered. It is well documented in literature that PBL enhances self-directed learning (Norman \& Schmidt, 1992; Schmidt \& Moust, 2000).

To consolidate students' learning, their geography teacher (the group facilitator who also is one of the researchers) requested them to submit a group learning report on the study of Madame Ho's scenario 2 weeks after the PBL field programme. It was expected that the students would conduct some more library research and revisit the site to collect more data. Unfortunately, when the report was handed in 2 weeks later, the outputs were similar to those that they had already presented in the second day of the PBL field programme. There was no new or additional information apart from their previous work. The students explained that there were two subject examinations within the 2 weeks which had significantly affected them in conducting further study or investigation of the scenario. The students seem unable to sustain the advantages of PBL with their subsequent work that did not allow them sufficient time to engage further in such self-directed empowered inquiry.

We also found that the PBL field programme did not seem able to sustain the positive effect on students' self-directed learning, particularly as A2 and A6 had the following in their reflective journal:

In PBL, I wanted to know the answers to the problems, but preferably from teachers. I'm not willing to find answers by myself. . . but I'm eager to ask questions in PBL. . I used to learn in a traditional way and I may not have the ability to adopt PBL learning style. . the teacher should do more follow-up work after the camp... (Hong Kong) students used to be forced to learn ... students lack active learning style... Don't expect students can realise what is self-directed learning in one learning activity. . . the concept of self-directed learning is too illusive to us... (A2 - journal data)

PBL may not be useful to me as I don't have enough knowledge to provide answers. This discourages me from further learning. . But the short field trip was more useful to me as learning was more convenient and immediate. (A6 - journal data)

The implication from these two journal entries strongly suggests that to make self-directed learning effective in the use of PBL in field work or any other meaningful teaching, the whole learning environment needs to be shaped holistically 
to allow the learning impact to be feasible. Any one-off or ad-hoc arrangement will not be enough to bring about any significant impact or change.

\section{Summary}

This paper has reported at great depth and length our first attempt to use PBL in a field programme with a group of seven geography students to see how they have experienced environmental learning in terms of knowledge, attitude, and behaviour. Though the sample size of a group of seven students is certainly small, the rich portrayal of how these seven students worked through the different stages of PBL has revealed and illuminated significantly different learning behaviours from those which they normally performed in more conventional field exercises.

Though this PBL field programme lasted only for 2 days and was solely focused on one problem, environmental learning had taken place. During the PBL field programme, the students had been provided a framework in which they learned to take full control of their own learning. The students identified the problem, set hypotheses, constructed their research methods and collected empirical data solely by themselves. In this empowered learning process, the students had acquired more in-depth knowledge and extended their learning into other subject disciplines. In doing so, they practiced and developed their critical thinking and problem-solving skills. Although we found no obvious and strong evidence of sustained self-directed learning among the students (probably due to the influence of other school work after their return from the field study), the PBL field programme had offered them a framework for further development of their self-directed learning if they wished to pursue it further.

If a longitudinal study of the same group of students could be conducted, the outcome and evidence of environmental learning through the use of PBL in the field might be more strongly substantiated. However, it was not possible for the researchers to conduct a second attempt to bring the same students to do another PBL field programme as they soon became fully engaged in preparing for their summative public examination for university admission. If provided with more time and problem statements in a longitudinal research study, we believe PBL in the field would eventually provide a clearer indication about whether student-participants are able to develop into self-directed learners or not. However, merely based on the findings from this 2-day PBL field programme, we have confidence to believe PBL in the field can offer a promising direction to accomplish the goals of education for the environment.

\section{Correspondence}

Any correspondence should be directed to Prof Tammy Kwan, Faculty of Education, The University of Hong Kong, Pokfulam, Hong Kong (tylkwan@ hkucc.hku.hk).

\section{References}

Ayres, F. (2002) Problem-based learning: The benefits to students and organizations. Training Journal February, 20-22. 
Baron, R.A. \& Byrne, D. (1994) Social Psychology: Understanding Human Interaction (7th edn). Boston: Allyn and Bacon.

Bligh, J. (1995) Problem-based learning in medicine: An introduction. Postgraduate Medical Journal 71 (836), 323-326.

Bogner, F.X. (1998) The influence of short-term outdoor ecological education on longterm variables of environmental perspective. The Journal of Environmental Education 29 (4), 17-29.

Casey, M.B., \& Howson, P. (1993) Educating pre-service students based on a problemcentered approach to teaching. Journal of Teacher Education 44 (5), 361-369.

Chan, L.S. (2003-05) Quality Education Fund Project - Problem-based Learning in the Field Environment. Department of Earth Sciences, The University of Hong Kong.

Clark, L.H. (1973) Teaching Social Studies in Secondary School: A Handbook. New York: Macmillan.

Curriculum Development Council (1999) Guidelines on Environmental Education in Schools. Hong Kong: The Education Department, Hong Kong SAR Government.

Curriculum Development Council (2000) Learning To Learn - The Way Forward in Curriculum Development. HK: The Curriculum Development Council, Hong Kong SAR Government.

Dewey, J. (1938) Experience and Education. New York: Collier.

Dolmans, D.A. \& Schmidt, H.G. (1994) What drives the student in problem-based learning? Medical Education 28, 372-380.

Evenson, D.H. \& Hmelo, C.E. (2000) Problem-Based Learning: A Research Perspective on Learning Interactions. London: Lawrence Erlbaum Associates.

Education and Manpower Bureau (2005) The New Academic Structure for Senior Secondary Education and Higher Education - Action plan for investigating in the future of Hong Kong. Hong Kong: Education and Manpower Bureau.

ETE (2005) Exploring the Environment (ETE, last update 28 April 2005) at http://www. cotf.edu/ete/.

Fien, J. (1993) Education for the Environment. Geelong: Deakin University Press.

Finkle, S.L., \& Torp, L.L. (1995) Introductory documents. Available from the Center for Problem-Based Learning, Illinois Math and Science Academy, Aurora, IL 60506-1000.

Gallagher, S.A., Stepien, W.J., Sher, B.T. \& Workman, D. (1994) Implementing problembased learning in science classroom. School Science and Mathematics 95 (3), 136-146.

Gardner, H. (1993) Frames of mind: The theory of multiple intelligences. New York: Basic Books.

Hewson, P.W. \& Thorley, N.R. (1989) The conditions of conceptual change in the classroom. International Journal of Science Education 11 (5), 541-553.

Hungerford, H.R. \& Volk, T.L. (1990) Changing learner behaviour through environmental education. The Journal of Environmental Education 21 (3), 8-21.

Johnson, D.W. \& Johnson, R.T. (1979) Conflict in the classroom: Controversy and learning. Review of Educational Research 49, 51-69.

Lin, M.H., Chiu, D.T.Y., Shih, S.R., Chou, Y.P., Shen, W.S. \& Shen, C.R. (2003) Performance of PBL in medical technology education. PBL in Action 1, 5-6.

Linn, M.C., Clement, C., Pulos, S. \& Sullivan, P. (1989) Scientific reasoning in adolescence: The influence of instruction in science knowledge and reasoning strategies. Journal of Research in Science Teaching 26 (2), 171-187.

Minstrell, J. (1989) Teaching Science for Understanding. In L.B. Resnick \& L.E. Klopfer (eds) Toward the Thinking Curriculum: Current Cognitive Research (pp. 129-149). Alexandra, VA: Association for Supervision and Curriculum Development.

Mouly, G.J. (1973) Psychology for Effective Teaching (3rd edn). New York: Holt, Rinehart and Winston.

Norman, G. \& Schmidt, H. (1992) The psychological basis of problem-based learning: A review of the evidence. Academic Medicine 67, 557-565.

Palmberg, I.E. \& Kuru, J. (2000) Outdoor activities as a basis for environmental responsibility. The Journal of Environmental Education 31 (4), 32-36.

Ramsey, C.E. \& Rickson, R.E. (1976) Environmental knowledge and attitudes. The Journal of Environmental Education 8 (1), 10-18. 
Roseberry, A.S., Warren, B. \& Conant, F.R. (1992) Appropriating scientific discourse: Findings from language minority classrooms. The Journal of the Learning Sciences 2 (1), 61-94.

Resenberg, M.J. \& Hovland, C.I. (1960) Attitude Organization and Change: An Analysis of Consistency among Attitude Components. New Haven: Yale University Press.

Schmidt, H.G. \& Moust, J.H.C. (2000) Factors affecting small-group tutorial learning: A review of research. In Evenson, D.H. \& Hmelo, C.E. (eds) Problem-Based Learning: A Research Perspective on Learning Interactions (Chap. 2, pp. 19-51). London: Lawrence Erlbaum Associates.

Stimpson, P. (2001) Environmental Attitudes and Education in Hong Kong. Hong Kong: The University of Hong Kong.

Vygotsky, L. (1978) Mind in Society. Cambridge, MA: Harvard University Press.

\section{Appendix}

Please consider the following 12 pairs of statements. Each pair represents two different points of view on a particular topic. (For each pair, place your views along the scale by circling one number between 1 and 5, where 1 means you strongly agree with the statement on the left, 3 means your views are evenly balanced between the two statements and 5 means you strongly agree with the statement on the right.)

1. Science and technology have improved our quality of life.

2. Because we are human, we are not subject to the laws of nature as are other species.

3. People should adapt to the environment whenever possible.

4. Modern technology has reduced our freedom and independence.

5. Natural resources should be saved for the benefits of future generations.

6. Modern industrial countries are very seriously disturbing the balance of nature.

7. The earth is like a spaceship, with limited room and resources.

8. People must learn to control nature in order to survive.

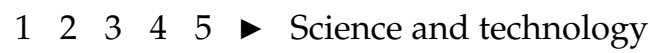
have worsened our quality of life.

$\begin{array}{lllll}1 & 2 & 3 & 4 & \end{array}$ Despite our special abilities, humans are subject to the laws of nature like other species.

$\begin{array}{lllll}1 & 2 & 3 & 4 & 5\end{array}$ The environment should be changed to meet people's needs.

$\begin{array}{lllll} & 2 & 3 & 4 & \end{array}$ Modern technology has increased our freedom and independence.

$\begin{array}{lllll}1 & 2 & 4 & 5\end{array}$ Natural resources should be used for the benefit of the present generation.

$\begin{array}{lllll}1 & 2 & 3 & 4 & 5\end{array}$ - The balance of nature is strong enough to cope with the impacts of modern industrial countries.

$4 \begin{array}{lllll}1 & 2 & 3 & 4 & 5\end{array}$ The earth is vast, with almost unlimited room and resources.

$\begin{array}{llllll} & 2 & 3 & 4 & \end{array}$ People must learn to live in harmony with nature to survive. 
9. Science and technology will always be able to find solutions to our problems.

10. Complex technologies will always be risky because of the chance of human error.

11. Economic growth should be given priority over environmental protection.

12. Nature should be used to produce goods for people. $\begin{array}{lllll}1 & 2 & 3 & 4 & 5\end{array}$

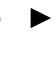

Science and technology often create more problems than they solve.

$\begin{array}{lllll}1 & 2 & 3 & 4 & 5\end{array}$ Complex technologies can be made virtually risk-free through continual improvements.

$\begin{array}{lllll}1 & 2 & 3 & 4 & 5\end{array}$ - Environmental protection should be given priority over economic growth.

$\begin{array}{lllll}1 & 2 & 3 & 4 & 5\end{array}$ Nature should be preserved for its own sake.

The 12 questions are used to reveal students' position between technological or environmental standing. Each question is provided with a Likert scale from 1 to 5, for students to indicate their preference. The scores of each question are added up to show an environmental score to reflect their ETP score. Based on the classification used by Stimpson (2001), 5 categories are identified along the ETP, from strong techno-centric to strong environmental beliefs. A negative ETPS represents techno-centricism while a positive figure means ecocentricism (see the following table).

Belief in an ETP and environmentalism

\begin{tabular}{|l|l|l|}
\hline ETP score & Environmental beliefs & Environmentalism \\
\hline-24 to -13 & Strong technological belief & Blue-green \\
\hline-12 to -1 & Technological belief & Light green \\
\hline 0 & Neutral position & Neutral \\
\hline+1 to +12 & Environmental belief & Red-green \\
\hline+13 to +24 & Strong environmental belief & Dark green \\
\hline
\end{tabular}


Copyright of International Research in Geographical \& Environmental Education is the property of Multilingual Matters and its content may not be copied or emailed to multiple sites or posted to a listserv without the copyright holder's express written permission. However, users may print, download, or email articles for individual use. 